\title{
Temporal Expression Patterns of Genes Related to Sex Steroid Action in Sexually Dimorphic Nuclei During Puberty
}

\author{
Moeko Kanaya ${ }^{\dagger}$ Masahiro Morishita and Shinji Tsukahara* \\ Division of Life Science, Graduate School of Science and Engineering, Saitama University, Saitama, Japan
}

\section{OPEN ACCESS}

Edited by:

Takayoshi Ubuka, Monash University Malaysia, Malaysia

Reviewed by:

Alexander S. Kauffman,

University of California,

San Diego, United States Victoria Bunik,

Lomonosov Moscow State

University, Russia

*Correspondence:

Shinji Tsukahara

stsuka@mail.saitama-u.ac.jp

tPresent address:

Moeko Kanaya,

Department of Anatomy and Neurobiology, Graduate School of Medicine, Nippon Medical School,

Tokyo, Japan

Specialty section:

This article was submitted to Neuroendocrine Science, a section of the journal Frontiers in Endocrinology

Received: 28 November 2017 Accepted: 16 April 2018

Published: 02 May 2018

Citation:

Kanaya $M$, Morishita $M$ and Tsukahara S (2018) Temporal Expression Patterns of Genes Related to Sex Steroid Action in

Sexually Dimorphic Nuclei During Puberty.

Front. Endocrinol. 9:213. doi: 10.3389/fendo.2018.00213
Sex steroids play a major role in sexually dimorphic brain development during not only the perinatal period but also the pubertal period. We previously showed that, in male mice, the estrogen receptor- $\alpha$ (Esr1) and aromatase (Cyp19a1) genes are essential to the sexually dimorphic formation of the anteroventral periventricular nucleus (AVPV) and the principal nucleus of the bed nucleus of the stria terminalis (BNSTp), but the estrogen receptor- $\beta$ (Esr2) gene is not necessary. We also showed that the androgen receptor (Ar) gene is essential to the sexually dimorphic formation of the BNSTp. These genes are expressed in the AVPV and BNSTp of perinatal mice. However, it remains unknown whether these genes are expressed in the AVPV and BNSTp during puberty, and whether the expression, if any, differs by sex, age, and brain region. Here, we dissected the AVPV and BNSTp from Nissl-stained brain sections of male and female mice on postnatal day (PD) 20 (prepuberty), PD30 (puberty onset in females), PD40 (puberty onset in males), and PD60 (young adult) using a laser microdissection system. We then examined the mRNA levels of Esr1, Esr2, Cyp19a1, and Ar in these brain regions. In the AVPV, Esr1 mRNA levels were greater in females than males during PD20-60. Esr2 and $\operatorname{Ar}$ mRNA expressions did not differ between sexes. Ar mRNA levels were higher at PD30 than PD20. Cyp19a1 mRNA was not detected in the AVPV at PD20-60. In the BNSTp, Esr1 and Esr2 mRNA levels were higher in females than in males during PD20-60, although the mRNA levels of Cyp19a1 and Ar did not differ between sexes. Additionally, we revealed that orchiectomy at PD20 induced a failure of normal formation of the male BNSTp and testosterone replacement in the prepubertal period rescued the effect of orchiectomy at PD20. Taken together, it is suggested that pubertal testosterone transported to the AVPV is not converted to estradiol there and does not act via ESR1 and ESR2. By contrast, the formation of the male BNSTp may be affected by testicular testosterone during puberty via AR and/or via ESR1 after conversion to estradiol by CYP19A1.

Keywords: aromatase, puberty, sex steroids, sexual differentiation, sexually dimorphic nucleus, sex steroid receptor, anteroventral periventricular nucleus, principal nucleus of the bed nucleus of the stria terminalis

\section{INTRODUCTION}

Sexually dimorphic nuclei underlie sex- and gender-specific functions in the brain. The anteroventral periventricular nucleus (AVPV) of the hypothalamus in rodents is a sexually dimorphic nucleus that is larger in size and contains more neurons in females than in males (1-4). Specifically, the female AVPV contains a larger number of neurons expressing tyrosine 
hydroxylase (TH) (3) and kisspeptin $(5,6)$. TH neurons in the AVPV promote parental behavior in female mice (7). Although TH neurons in the AVPV do not promote parental behavior in male mice, they suppress inter-male aggression (7). Kisspeptin neurons in the female AVPV appear to participate in the estradiol-induced surge of luteinizing hormone $(8,9)$. The principal nucleus of the bed nucleus of the stria terminalis (BNSTp) is a sexually dimorphic nucleus in the forebrain that is larger and contains a greater number of neurons in male rodents (10-13). Males have a greater number of vasopressin neurons in the BNSTp, which are involved in anxiety, aggressive behavior, and stress responses (14), and which project to the lateral septum (15-17). These differences in vasopressin neurons may underlie behavioral sex differences, particularly as male rodents exhibit more anxiety-related behavior than females $(18,19)$.

In male rodents, sexually dimorphic nuclei are formed by the influence of testicular testosterone during the perinatal period $(20,21)$. Like the AVPV in male rats, the AVPV in female rats treated with testosterone postnatally is smaller and contains fewer TH neurons and kisspeptin neurons in adulthood $(6,22)$. We previously showed that the volume and number of neurons in the AVPV are increased in male mice with deletion of the estrogen receptor- $\alpha(E s r 1)$ and aromatase (Cyp19a1) genes, but are not affected by deletion of the estrogen receptor- $\beta$ (Esr 2$)$ or androgen receptor (Ar) gene (23). These previous findings suggest that Esr1 and Cyp19a1 are essential to the formation of the male AVPV, but Esr2 and Ar are not necessary. In support of this notion, Esr1 and Cyp19a1 mRNAs are expressed in the AVPV in perinatal mice (23). Postnatal treatment with estradiol, as well as testosterone, reduces the number of neurons in the AVPV in adult female rats (24). Thus, testicular testosterone in the perinatal period might be converted by CYP19A1 in the AVPV to estradiol, which signals through ESR1 to defeminize the morphology of the AVPV.

Perinatal testicular testosterone also affects the BNSTp, although the effects are opposite to those on the AVPV. The volume and number of neurons in the BNSTp in adult male rats are decreased by neonatal orchiectomy (12). Postnatal treatment with testosterone or estradiol increases the number of neurons in the BNSTp of adult female mice (25). The volume and number of neurons in the BNSTp in male mice are reduced to levels similar to those in females by deletion of Esr1 or Cyp19a1, but not Esr2 (26). Esr1 and Cyp19a1 are expressed in the BNSTp in perinatal mice (23). These findings suggest that the formation of the male BNSTp involves the action of estradiol (produced by the aromatization of testosterone) via ESR1 during the perinatal period. Additionally, the AR plays an important role in the formation of the male BNSTp, because the volume and number of neurons in the BNSTp are smaller in male $A r$ knockout (KO) mice, compared with wild-type males, similar to females (23). Ar is not expressed in the murine BNSTp prenatally, but begins expression early in the postnatal period $(23,27)$. The formation of the male BNSTp might require not only estradiol, formed from the aromatization of testosterone, acting via ESR1 in the perinatal period, but also testosterone acting via AR postnatally.
Accumulating evidence shows that testicular testosterone during the perinatal period is essential for the sexually dimorphic formation of brain structures. However, the formation of sexually dimorphic nuclei is affected by pubertal gonadal hormones as well $(28,29)$. In male mice, the BNSTp contains a comparatively greater number of calbindin neurons (30). This sex difference in calbindin neurons emerges before puberty, and increases further as calbindin neurons continue to increase in males and decrease in females during the pubertal and adolescent periods $(31,32)$. Testicular hormones during puberty also contribute to the formation of the male BNSTp, because the increase in calbindin neurons in the male BNSTp is perturbed by prepubertal orchiectomy, although the decrease in the female BNSTp is not altered by prepubertal ovariectomy (32). The sexually dimorphic formation of the AVPV might be influenced by pubertal ovarian hormones. Prepubertal ovariectomy decreases the volume and number of neurons in the AVPV in female rats (33). Thus, gonadal hormones during puberty play an important role in the sexually dimorphic formation of the AVPV and BNSTp; however, it remains unknown whether genes related to gonadal hormone actions are expressed in the sexually dimorphic nuclei during puberty.

In this study, we aimed to determine whether the AVPV and BNSTp of pubertal mice express genes involved in gonadal hormone actions, and whether the expression, if any, varies by sex, age, and brain-region. First, using tissue samples isolated precisely and accurately from the AVPV and BNSTp of peripubertal mice, we evaluated the mRNA expression patterns of Esr1, Cyp19a1, and $A r$, which play an essential role in the sexually dimorphic formation of the AVPV and/or BNSTp $(23,26)$, as well as that of Esr2. As a result, the mRNA of Cyp19a1 was expressed in the BNSTp, but not in the AVPV of peripubertal mice, suggesting that the BNSTp of male mice is affected by estradiol, which is converted from testicular testosterone by CYP19A1 locally there during puberty, but the AVPV is not. Next, to determine whether testicular testosterone during puberty contributes to the formation of the male BNSTp, we investigated the effects of prepubertal orchiectomy and testosterone replacement on the morphology of the BNSTp in adulthood with reference to calbindin expression.

\section{MATERIALS AND METHODS}

\section{Animals}

Adult male and female C57BL/6J mice for breeding were purchased from Sankyo Labo Service Corporation (Tokyo, Japan). Offspring derived from mating in our facility were housed with dams in the same cages until weaning on postnatal day (PD) 21 $(\mathrm{PD0}=$ day of birth). All animals were bred and housed in a room with a controlled temperature $\left(22^{\circ} \mathrm{C}\right)$ and a 12 -h light/12-h dark cycle (lights on: 08:00-20:00). Standard diet and tap water were available ad libitum. All animal experimental procedures were approved by the Animal Care and Experimentation Committee of Saitama University and were conducted in accordance with the Guidelines for the Care and Use of Experimental Animals of Saitama University. 


\section{Gene Expression Analysis of the AVPV and BNSTp in Peripubertal Mice \\ Brain Tissue Collection}

Male and female mice of different ages $\{\mathrm{PD} 20$, prepuberty; $\mathrm{PD} 30$, puberty onset in females; PD40, puberty onset in males; and PD60, young adult [see review by Piekarski et al. (34)]\} were deeply anesthetized by intraperitoneal injection of sodium pentobarbital $(64.8 \mathrm{mg} / \mathrm{kg}$ body weight $)$ and decapitated. Fresh brains were quickly frozen in hexane chilled to $-80^{\circ} \mathrm{C}$ and stored at $-80^{\circ} \mathrm{C}$ until further processing. There are several studies showing that the levels of Esr $1 \mathrm{mRNA}$ and protein in the preoptic area $(35,36)$ and the number of ESR1- and AR-immunoreactive cells in the BNSTp $(37,38)$ are affected by circulating estradiol. Therefore, we compared the mRNA levels of Esr1, Esr2, Cyp19a1, and $A r$ in the AVPV and BNSTp of diestrous and proestrous female mice. When collecting brains from females on PD40 or PD60, vaginal smears were performed starting on the day of vaginal opening, and animals in the diestrous or proestrous phase were sacrificed between 12:00 hours and 14:00 hours on PD40 or PD60. As a result, unexpectedly, diestrous and proestrous female mice did not differ with regard to the mRNA levels of Esr1, Esr2, and Ar in the AVPV and BNSTp (data not shown). Cyp19a1 mRNA was not detected in the AVPV on PD40 and PD60. Cyp19a1 mRNA in the BNSTp did not differ between diestrous and proestrous females on PD40 and PD60 (data not shown). In this study, diestrous and proestrous female mice of the same age were therefore combined into a single group. The numbers of animals used for this study were as follows: PD20 male, $n=6$; PD20 female, $n=4$; PD30 male, $n=4$; PD30 female, $n=5$; PD40 male, $n=4$; PD40 female, $n=6$; PD60 male, $n=4$; PD60 female, $n=8$.

\section{Isolation of the AVPV and BNSTp}

The AVPV and BNSTp were dissected using a laser microdissection (LMD) system (Leica LMD 7000; Leica Microsystems, Wetzlar, Germany) in accordance with the procedure reported previously, with slight modification (23). Briefly, frozen brains were coronally cut at a thickness of $30 \mu \mathrm{m}$ on a cryostat. Brain sections containing the AVPV and BNSTp were obtained in the coronal plane $0.38-0.02 \mathrm{~mm}$ rostral to the bregma and $0.10-0.34 \mathrm{~mm}$ caudal to the bregma, respectively, according to the mouse brain atlas (39). Brain sections containing the AVPV or BNSTp were mounted on PEN membrane slides (Leica Microsystems), fixed with ice-cold 5\% acetic acid in ethanol for $3 \mathrm{~min}$, stained with ice-cold $0.2 \%$ cresyl fast violet for $1 \mathrm{~min}$, rinsed in $100 \%$ ethanol for $1 \mathrm{~min}$, and dried with cool air. The AVPV and BNSTp were then dissected out from cresyl fast violetstained brain sections by the LMD system and collected in a tube containing $70 \mu \mathrm{L}$ RNA extraction buffer and $5 \mu \mathrm{L}$ carrier RNA working solution $(4 \mathrm{ng} / \mu \mathrm{L})$ from the RNeasy Micro Kit (Qiagen, Valencia, CA, USA). To confirm whether the AVPV and BNSTp were precisely collected, we measured the volume of the nuclei. If the AVPV and BNSTp were correctly isolated, a sex difference in the volume of the nuclei could be found. The areas of the dissected tissue fragments were recorded by the LMD system. We calculated the volume of the acquired tissues by multiplying total of the areas of the dissected tissue fragments by the thickness of brain sections $(30 \mu \mathrm{m})$ for each sample.

\section{Quantification of mRNA Levels}

Total RNA was extracted and purified using the RNeasy Micro Kit (Qiagen) according to the manufacturer's protocol. Firststrand cDNA was synthesized using the TaKaRa Prime Script RT reagent kit (TaKaRa Bio, Otsu, Japan). For each sample, total RNA (approximately $160 \mathrm{ng}$ ) was reverse-transcribed to first-strand cDNA in a final volume of $15 \mu \mathrm{L}$ Prime Script buffer containing Prime Script RT Enzyme Mix I $(0.75 \mu \mathrm{L})$ and random hexamers (75 pmol). Standard samples for Esr1, Cyp19a1, $A r$, and glyceraldehyde-3-phosphate dehydrogenase (Gapdh), a housekeeping gene, were prepared by mixing an equal amount of each cDNA sample and serially diluting in EASY Dilution solution (TaKaRa Bio). To prepare standard samples for Esr2, cDNA obtained from the hypothalamus of adult mice was serially diluted.

Quantitative polymerase chain reaction (qPCR) was performed using a Light Cycler ST300 (Roche Diagnostics, Mannheim, Germany). A 2- $\mu \mathrm{L}$ aliquot of standard or unknown sample was amplified in a $20-\mu \mathrm{L}$ reaction mixture containing $200 \mathrm{nM}$ of each gene-specific primer [Gapdh forward primer: CACTGCCACC CAGAAGA, Gapdh reverse primer: TCCACGACGGACACATT; other genes were designed according to our previous study (23)] and $10 \mu \mathrm{L}$ of $2 \times$ SYBR Premix Ex Taq (TaKaRa Bio). The thermocycling parameters for qPCR were $30 \mathrm{~s}$ at $95^{\circ} \mathrm{C}$, followed by 40 cycles of $95^{\circ} \mathrm{C}$ for $5 \mathrm{~s}$ and $60^{\circ} \mathrm{C}$ for $20 \mathrm{~s}$. After qPCR, melting curve analysis was performed to assess the specificity of the PCR products. This analysis showed that the melting curves for the PCR products all had a single peak (data not shown).

qPCR analysis for Gapdh mRNA in the AVPV and BNSTp revealed that Gapdh mRNA levels in these nuclei did not differ significantly by sex or age (data not shown). Therefore, the amount of Esr1, Esr2, Cyp19a1, and Ar mRNAs was normalized by dividing by the amount of Gapdh mRNA for each sample.

\section{Morphological Analysis of the BNSTp in Male Mice Prepubertal Orchiectomy and Testosterone Replacement}

At PD20, male mice were orchiectomized and subcutaneously implanted with a Silastic tube $[1.02 \mathrm{~mm}$ inner diameter, $2.16 \mathrm{~mm}$ outer diameter, $10.9 \mathrm{~mm}$ in total length (effective length: $6.9 \mathrm{~mm}$ ); Dow Corning Corporation, Midland, MI, USA] containing testosterone (Sigma-Aldrich, St. Louis, MO, USA; $n=5$ ) or cholesterol (Wako Pure Chemical Industries, Osaka, Japan; $n=5$ ). The testosterone implantation was designed to produce the levels of serum testosterone in young male mice (Tsukahara, unpublished data). Surgery was performed under isoflurane inhalational anesthesia (concentration, $1.5 \%$ in air; flow rate, $1 \mathrm{~L} / \mathrm{min}$ ). Additionally, we prepared gonadally intact males $(n=5)$.

\section{Tissue Preparation}

At 10 weeks of ages, all animals were deeply anesthetized by intraperitoneal injection of sodium pentobarbital $(64.8 \mathrm{mg} / \mathrm{kg}$ body weight) and transcardially perfused with $0.05 \mathrm{M}$ ice-cold 
phosphate-buffered saline (PBS; $\mathrm{pH}, 7.4$ ) followed by ice-cold $4 \%$ paraformaldehyde in $0.05 \mathrm{M}$ phosphate buffer ( $\mathrm{pH}, 7.4)$. Brains were postfixed with the same fixative at $4^{\circ} \mathrm{C}$ overnight and then immersed in $30 \%$ sucrose in $0.05 \mathrm{M}$ phosphate buffer at $4^{\circ} \mathrm{C}$ for 2 days. Fixed brains were quickly frozen, coronally sectioned at a thickness of $30 \mu \mathrm{m}$ using a cryostat, and collected at $60-\mu \mathrm{m}$ intervals.

\section{Immunohistochemistry for Calbindin}

Brain sections were rinsed in 0.05 M PBS containing 1\% Triton $\mathrm{X}-100$ (PBST) and placed in $0.6 \% \mathrm{H}_{2} \mathrm{O}_{2}$ in PBST for $30 \mathrm{~min}$ at room temperature. The sections were then placed in 5\% normal goat serum in PBST for $1 \mathrm{~h}$ at room temperature and were reacted with a mouse monoclonal anti-calbindin antibody (1:15,000; C9848; Sigma-Aldrich; RRID: AB_476894) in 5\% normal goat serum-containing PBST at $4^{\circ} \mathrm{C}$ over two nights. After rinsing in PBST, the sections were reacted with peroxidase-labeled polymer conjugated to goat anti-mouse immunoglobulin (K4001, Dako, Carpinteria, CA, USA) for $1 \mathrm{~h}$ at room temperature. Calbindin immunoreactivity was visualized with a chromogenic substrate, 3,3'-diaminobenzidine (liquid DAB plus substrate chromogen system, Dako). Immunostained sections were mounted on gelatin-coated glass slides, air dried, dehydrated in ascending ethanol, cleared with xylene, and cover-slipped with a mounting medium.

\section{Morphometric Analysis}

The volumes of the BNSTp and the number of calbindinimmunopositive (calbindin-ir) cells in the BNSTp were measured using a light microscope equipped with a charge-coupled device camera (CX9000; MBF Bioscience, Williston, VT, USA) and a computer running Stereo Investigator software (MBF Bioscience). The outlines of the BNSTp on the left of the midline were traced to measure the volume. Calbindin-ir cells in the BNSTp were then counted using the optical fractionator method. Detailed parameters of the stereological analyses are as follows: section thickness, $30 \mu \mathrm{m}$; section interval, $60 \mu \mathrm{m}$; sampling grid size, $150 \mu \mathrm{m} \times 150 \mu \mathrm{m}$; counting frame size, $50 \mu \mathrm{m} \times 50 \mu \mathrm{m}$; dissector height, 13-16 $\mu \mathrm{m}$; and guard zone height, $1.5 \mu \mathrm{m}$.

\section{Statistical Analysis}

Two-way analysis of variance (ANOVA) was used to assess the effects of sex and age and the interaction between main factors on AVPV and BNSTp volume and the mRNA levels of target genes. The test of simple main effects was conducted when the interaction between main factors was significant in the two-way ANOVA. If there was a significant effect of age, but no significant interaction between sex and age, Bonferroni post hoc test was used to compare the mRNA levels of target genes between the different age groups. Differences in BNSTp volume and the number of calbindin-ir cells in the BNSTp among intact males, males subjected to prepubertal orchiectomy and cholesterolimplantation, and males subjected to prepubertal orchiectomy and testosterone implantation were analyzed with one-way ANOVA followed by Bonferroni post hoc test where appropriate. IBM SPSS Statistics v20.0 (IBM, Armonk, NY, USA) was used for data analyses. $P<0.05$ was considered statistically significant. A post hoc power analysis was carried out after data has been collected to determine the power in this study using $\mathrm{G}^{\star}$ Power 3 (40), a free power analysis program.

\section{RESULTS}

\section{AVPV and BNSTp Volume on PD20-60}

Tissues from the AVPV were collected from cresyl fast violetstained brain sections using the LMD system for accuracy and precision (Figure 1A). Two-way ANOVA indicated that the volume of the AVPV was significantly larger in females than in males $\left[F_{1,32}=13.86, p<0.005\right.$, power $(1-\beta)=0.98$; Figure $1 \mathbf{B}$ inset], and that it increased significantly with age from PD20 to $\operatorname{PD} 60\left[F_{3,32}=4.70, p<0.01\right.$, power $(1-\beta)=0.93$; Figure 1B $]$, although there was no significant interaction between sex and age [power $(1-\beta)=0.10$ ]. AVPV tissue volumes in PD30 mice were significantly greater $(p<0.05)$ than PD20 mice and did not differ from those in PD40 and PD60 mice.

Tissues from the BNSTp were isolated from cresyl fast violetstained brain sections using the LMD system (Figure 2A). BNSTp volume was significantly greater in PD20-60 males than in
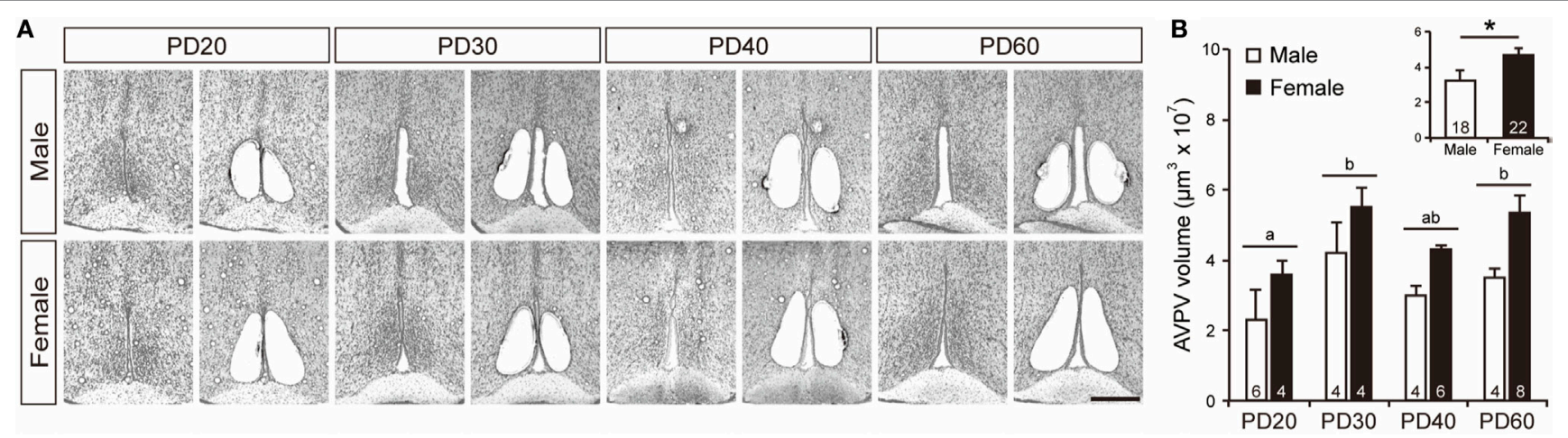

FIGURE 1 | Isolation of the AVPV. (A) Representative photographs showing brain sections before and after the AVPV was isolated in male and female mice on PD20-60. Scale bar indicates $400 \mu \mathrm{m}$. (B) The volume of AVPV tissues isolated from the brain of male and female mice on PD20, PD30, PD40, and PD60. The inset graph in panel (B) indicates the average volume of the AVPV in all ages. The numbers in the columns indicate the numbers of animals. Values are the mean \pm SEM. Differences in values that are significantly $(p<0.05)$ different from each other are indicated with letters. ${ }^{*} p<0.05$. 

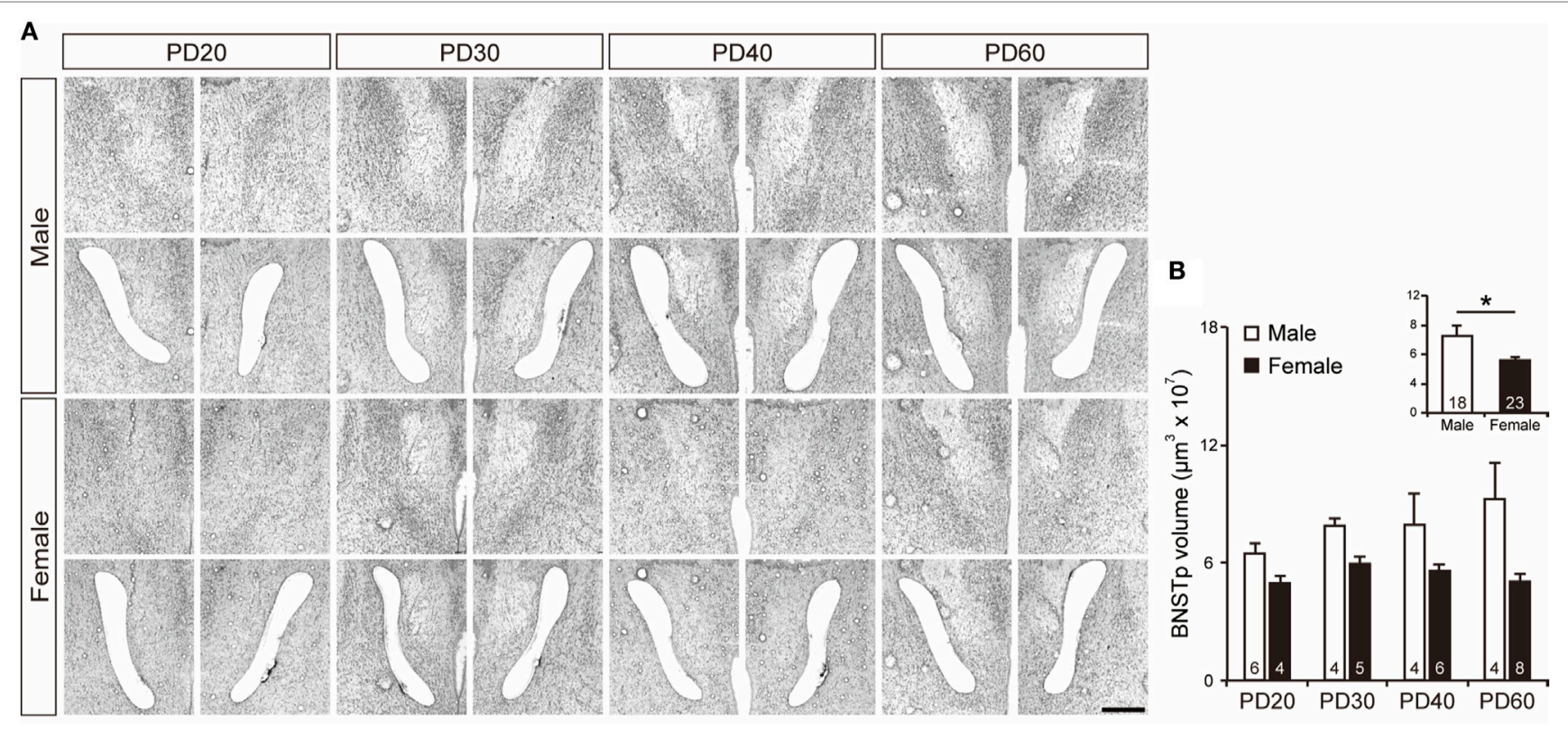

FIGURE 2 | Isolation of the BNSTp. (A) Representative photographs showing brain sections before and after the BNSTp was isolated in male and female mice on PD20-60. Scale bar indicates $400 \mu \mathrm{m}$. (B) The volume of BNSTp tissues isolated from the brain of male and female mice on PD20, PD30, PD40, and PD60. The inset graph in panel $\mathbf{( B )}$ indicates the average volume of the BNSTp in all ages. The numbers in the columns indicate the numbers of animals. Values are the mean \pm SEM. * $p<0.05$.

PD20-60 females $\left[F_{1,33}=16.33, p<0.0001\right.$, power $(1-\beta)=0.99$; Figure 2B inset]. The main effect of age and the interaction between sex and age on BNSTp volume were not significant [power $(1-\beta)=0.68$ and 0.58 , respectively; Figure 2B].

\section{Expression of Esr1, Esr2, Cyp19a1, and Ar mRNA in the AVPV on PD20-60}

Although the effect of age and interaction between sex and age on Esr 1 mRNA levels were not significant [power $(1-\beta)=0.68$ and 0.63, respectively], Esr1 mRNA levels in the AVPV at PD20-60 were significantly higher in females than in males $\left[F_{1,32}=35.75\right.$, $p<0.0001$, power $(1-\beta)=1.00$; Figure 3A inset]. Esr 2 mRNA levels in the AVPV were not significantly affected by sex, age, and their interaction [power $(1-\beta)=0.56,0.25$ and 0.20 , respectively; Figure 3B]. Ar mRNA levels in the AVPV was affected significantly by age $\left[F_{3,32}=3.03, p<0.05\right.$, power $\left.(1-\beta)=0.76\right]$, but not by sex [power $(1-\beta)=0.53$ ] and the interaction between sex and age [power $(1-\beta)=0.34]$. Ar mRNA levels in the AVPV of PD30 mice were significantly higher $(p<0.05)$ than those of PD20 mice and comparable with those of PD40 and PD60 mice (Figure 3C). Cyp19a1 mRNA in the AVPV on PD20-60 was at an undetectable level in most animals in either sex. Cyp19a1 mRNA was detectable in one female each on PD20, PD30, and PD40, in two males at PD30, and in two males and two females at PD60, but at the limit of detection by qPCR (data not shown).

\section{Expression of Esr1, Esr2, Cyp19a1, and Ar mRNA in the BNSTp on PD20-60}

There was a significant effect of sex $\left[F_{1,33}=51.56, p<0.0001\right.$, power $(1-\beta)=1.00$ ] on Esr 1 mRNA levels in the BNSTp during
PD20-60 (Figure 4A inset). However, the Esr1 mRNA levels were not significantly affected by age [power $(1-\beta)=0.12$ ] and by interaction between sex and age [power $(1-\beta)=0.51$ ]. Esr2 mRNA levels in the BNSTp were significantly higher in females than in males at PD20-60 $\left[F_{1,33}=4.35, p<0.05\right.$, power $(1-\beta)=0.62$; Figure 4B inset], although they did not significantly change with age [power $(1-\beta)=0.07$ ] and were not affected by the interaction between sex and age [power $(1-\beta)=0.08]$ (Figure 4B). Unlike the AVPV, the BNSTp expressed Cyp19a1 mRNA at PD20-60 (Figure 4C). Cyp19a1 mRNA levels in the BNSTp did not significantly change with sex and age [power $(1-\beta)=0.22$ and 0.24 , respectively]. The interaction of sex and age was also not significant on the Cyp19a1 mRNA levels [power $(1-\beta)=0.22$ ]. Ar mRNA levels in the BNSTp during PD20-60 were not significantly impacted by sex, age, and their interaction [power $(1-\beta)=0.24,0.73$ and 0.40, respectively] (Figure 4D).

\section{Effects of Prepubertal Orchiectomy and Testosterone Replacement on the BNSTp in Male Mice}

One-way ANOVA revealed that BNSTp volume $\left[F_{2,12}=7.07\right.$, $p<0.01$, power $(1-\beta)=0.92]$ and the number of calbindin-ir cells in the BNSTp $\left[F_{2,12}=6.98, p<0.05\right.$, power $\left.(1-\beta)=0.92\right]$ of adult male mice were significantly different among the experimental groups. BNSTp volume in males that were orchiectomized and implanted with cholesterol at PD20 was significantly smaller $(p<0.05)$ than that in gonadally intact males (Figures 5A,B). However, BNSTp volume in males that were orchiectomized and implanted with testosterone at PD20 was similar to that in 

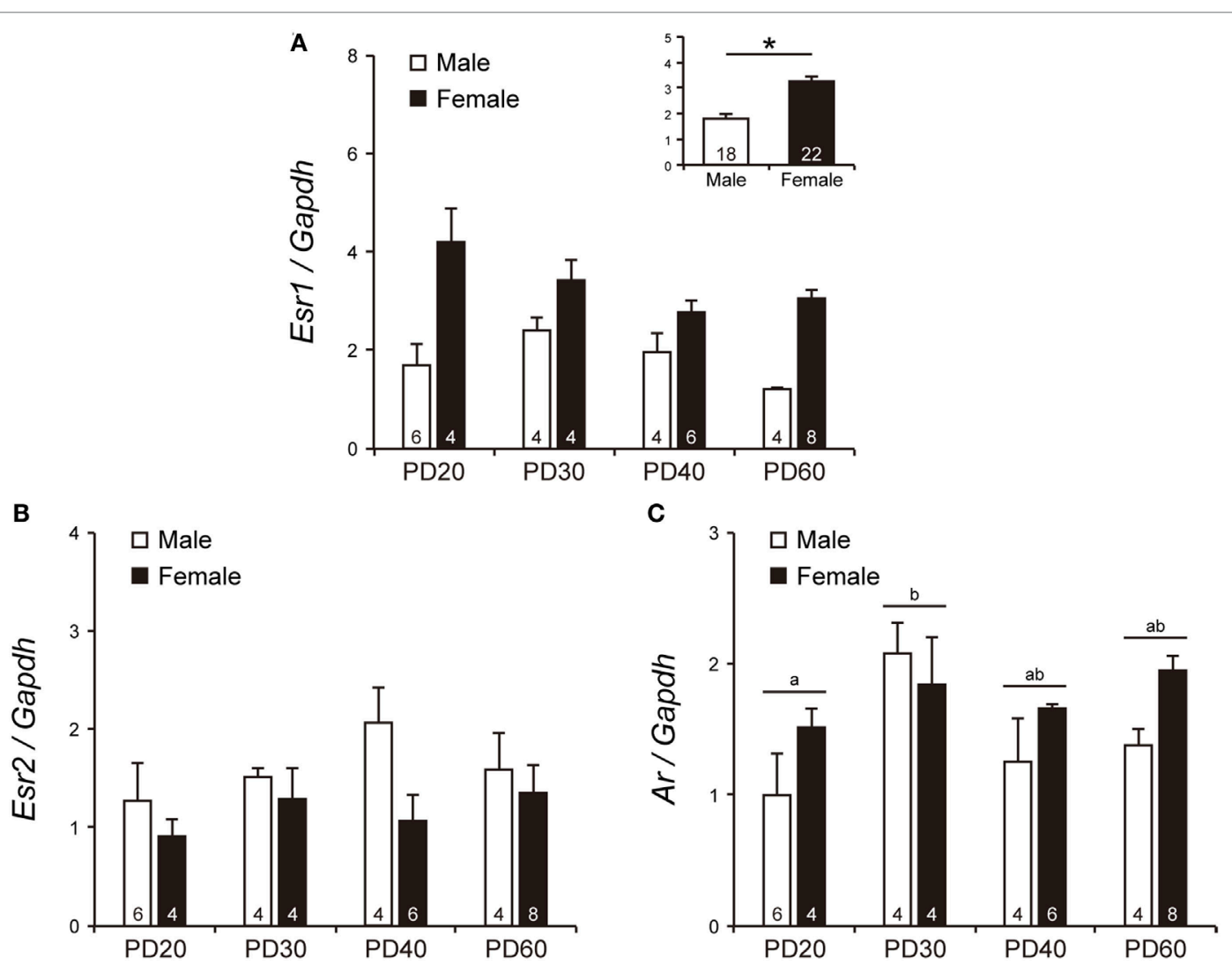

FIGURE 3 | The mRNA levels of Esr1, Esr2, and Ar in the AVPV of peripubertal mice. The mRNA levels of Esr1 (A), Esr2 (B), and Ar (C) in male and female mice on PD20, PD30, PD40, and PD60. The inset graph in panel (A) indicates the average mRNA level of Esr1 in all ages. The numbers in the columns indicate the numbers of animals. Values are the mean \pm SEM. Differences in values that are significantly $(p<0.05)$ different from each other are indicated with letters. ${ }^{\star} p<0.05$.

gonadally intact males and was significantly greater $(p<0.05)$ than that in the orchidectomzied and cholesterol-implanted males (Figures 5A,B). Likewise, the number of calbindin-ir cells in the BNSTp was significantly smaller $(p<0.05)$ in the orchiectomized and cholesterol-implanted males than in gonadally intact males (Figure 5C). The cell number in the orchiectomized and testosterone-implanted males was significantly larger $(p<0.05)$ than that in the orchiectomized and cholesterol-implanted males and was similar to that in gonadally intact males.

\section{DISCUSSION}

Here, we examined the mRNA levels of Esr1, Esr2, Cyp19a1, and $A r$ in the AVPV and BNSTp of peripubertal mice. To the best of our knowledge, this is the first study to examine these mRNA expressions to investigate the role of gonadal hormones during puberty in the formation of sexually dimorphic structures in the AVPV and BNSTp. We revealed that these genes are expressed in a sex-, age-, and region-specific manner. Especially, Cyp19a1 mRNA was expressed in the BNSTp but not in the AVPV on PD20-60. This suggests that the AVPV and BNSTp respond differentially to testicular testosterone, which might contribute to the sexually dimorphic development of these brain structures.

\section{Role of Sex Steroids in the Development of the AVPV}

We previously showed that the volume and neuron number in the AVPV of male mice lacking Esr1 and Cyp19a1 are larger than those of wild-type males and similar to those of females, although the volume and neuron number in the AVPV of male mice lacking Esr2 are comparable to those of wild-type males (23). We further showed that the AVPV expresses Esr1 and Cyp19a1 in the perinatal period (23). Additionally, it has been reported that administration of testosterone to postnatal female rats reduces AVPV volume and the number of TH and kisspeptin neurons in this structure in adulthood $(6,22)$. In this study, we found that the AVPV expressed Esr1 and Esr2, but not Cyp19a1 during PD20-60. This finding suggests that testicular testosterone in the peripubertal period is not converted to estradiol locally in the AVPV and does not affect the AVPV of male mice via ESR1 and ESR2, although it is not ruled out that estradiol produced elsewhere can affect the AVPV. Taken together, it is suggested that the morphology of the male AVPV might be organized by estradiol, which is synthesized from testicular testosterone by CYP19A1 (aromatase) expressed locally in the AVPV, which signals via ESR1 in the perinatal, but not pubertal period. Here, we found that $A r$ mRNA was expressed in the AVPV during puberty. However, AR-mediated testosterone signaling might 

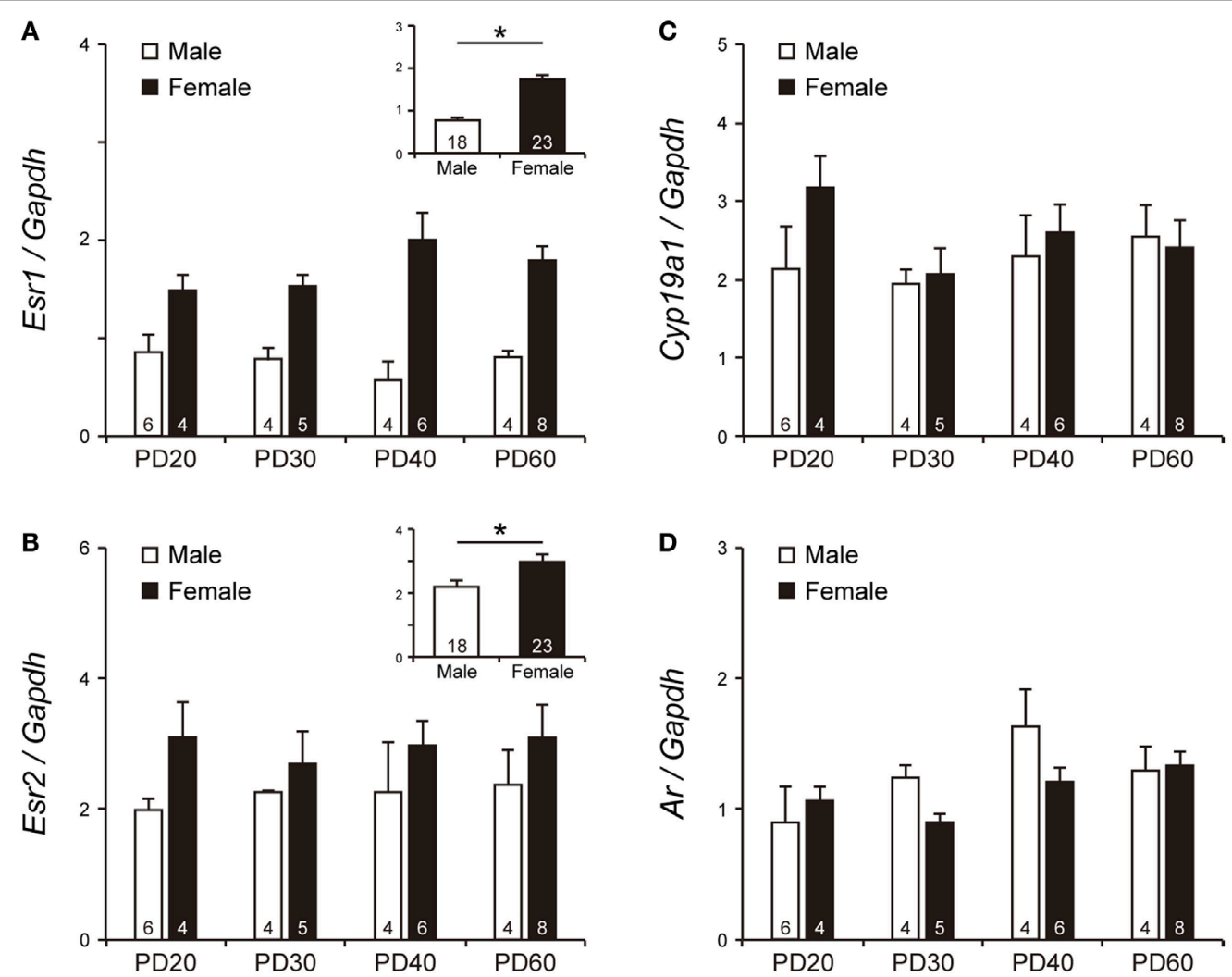

FIGURE 4 | The mRNA levels of Esr1, Esr2, Cyp19a1, and Ar in the BNSTp of peripubertal mice. The mRNA levels of Esr1 (A), Esr2 (B), Cyp19a1 (C), and Ar (D) in male and female mice on PD20, PD30, PD40 and PD60. The inset graphs in panels (A,B) indicate the average mRNA level of Esr1 and Esr2 in all ages, respectively. The numbers in the columns indicate the numbers of animals. Values are the mean \pm SEM. ${ }^{*} p<0.05$.

not be necessary for the organization of the AVPV in male mice, because the volume and neuron number in the AVPV of $\mathrm{Ar} \mathrm{KO}$ male mice is comparable to those of wild-type male mice (23). Additionally, the AVPV in male rats appears to be not affected by prepubertal orchiectomy (33), suggesting that testicular hormones during puberty contribute minimally to the organization of the AVPV in male mice.

Esr 1 and Esr 2 were expressed in the female AVPV from PD20 to PD60. Given that ovaries begin to produce estradiol on PD7 (41), ovarian estradiol could act on the AVPV through ESR1 and ESR2 during the peripubertal period. We found here that AVPV volume increased from PD20 to PD30, and remained high on PD60, and that it was greater in female mice compared with male mice. During puberty in rats, newborn cells are incorporated into the AVPV, more so in females than in males, and this incorporation of new cells is suppressed by ovariectomy on PD20 (33). Thus, ovarian estradiol, signaling through ESR1 and/or ESR2 during puberty, might promote the generation of AVPV cells, which could contribute to the sexually dimorphic development of the AVPV.

\section{Role of Sex Steroids in the Development of the BNSTp}

We previously reported that the masculinization of the BNSTp is disrupted in male mice lacking Esr1, Cyp19a1, or Ar, but not
Esr2 (23). We further found that the BNSTp expresses mRNAs of Esr1 and Cyp19a1 in the perinatal period and Ar mRNA in the postnatal period (23). Neonatal orchiectomy decreases the volume and number of neurons in the BNSTp of adult male rats (12), and early postnatal treatment with testosterone or estradiol increases the number of neurons in the BNSTp of adult female mice (25). These findings suggest that testosterone, acting through $\mathrm{AR}$, during the postnatal period, and aromatized testosterone (estradiol), acting through ESR1, during the perinatal period help to masculinize the morphology of the BNSTp. In addition, it is thought that pubertal gonadal hormones affect the formation of the BNSTp. The BNSTp in prepubertal male mice has a greater volume and contains a larger number of calbindin neurons than the BNSTp of female mice of the same age $(31,32)$, and these sex differences become more pronounced over time, with a gradual increase in these parameters in males and a gradual decrease in females during puberty $(31,32)$. The increase in the volume and calbindin neuron number of the male BNSTp is suppressed by orchiectomy on PD20 (32). In this study, we confirmed that orchiectomy at PD20 reduced BNSTp volume and calbindin-ir cell number of the BNSTp in adult male mice. Moreover, we revealed that a compensatory treatment with testosterone could rescue the effects of orchiectomy at PD20 on the BNSTp in male mice. These findings suggest that testicular testosterone during puberty plays an important role in the formation of the male 


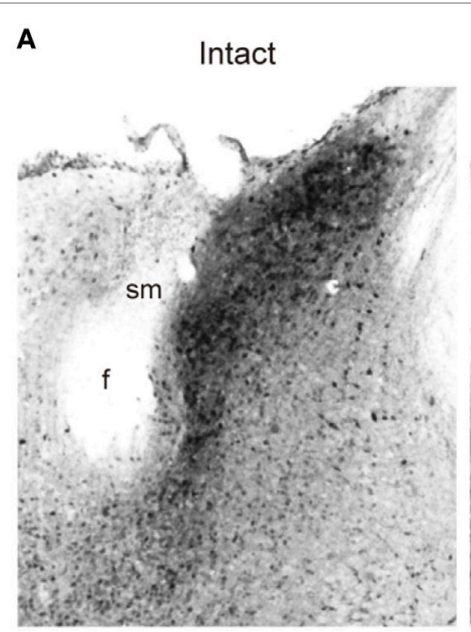

B

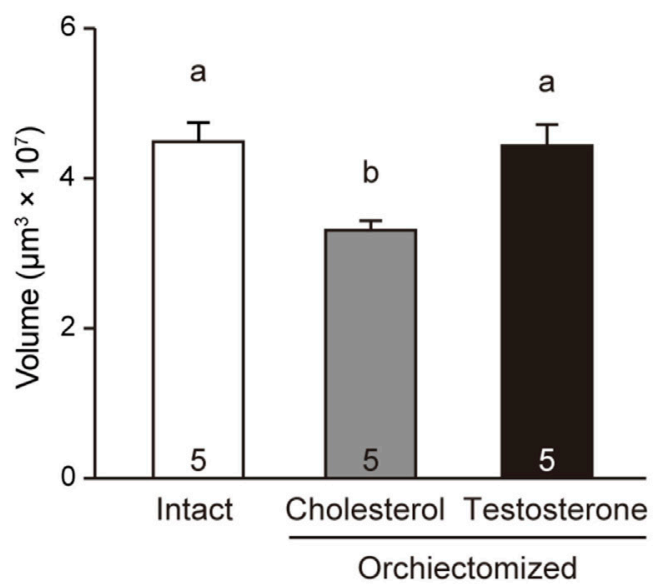

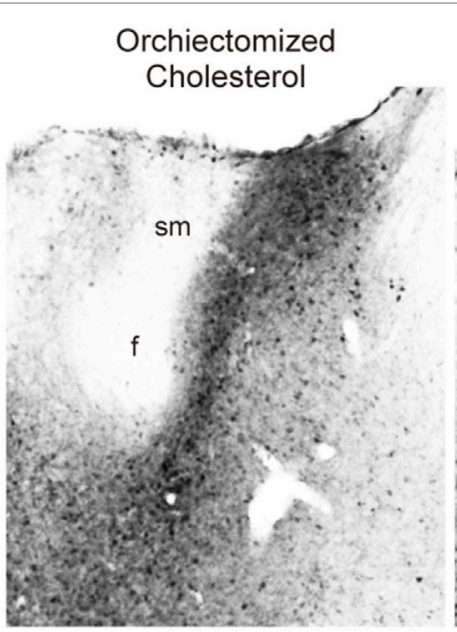

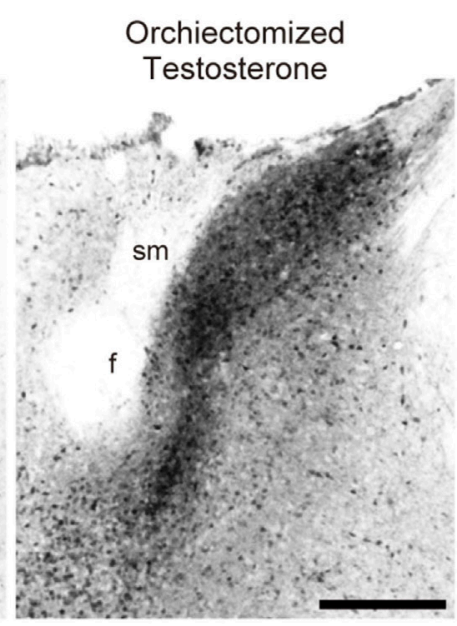

C

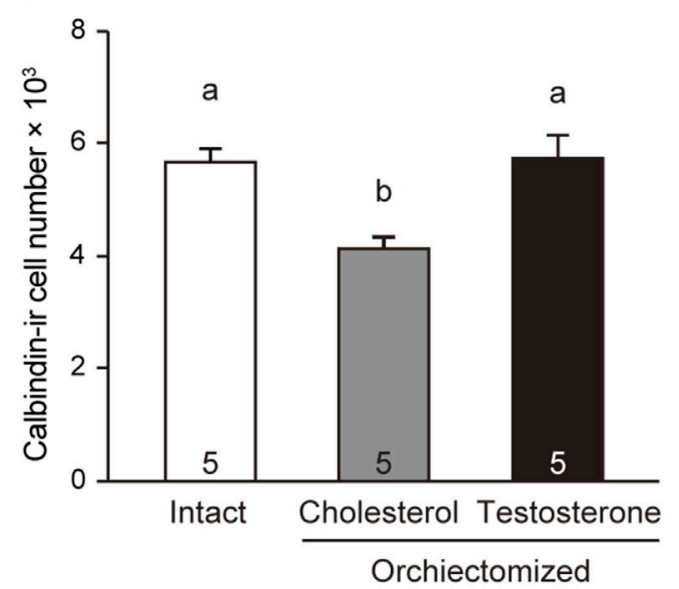

FIGURE 5 | Effects of peripubertal testicular testosterone on the BNSTp in male mice. (A) Representative photomicrographs of brain sections from a gonadally intact adult male mouse, an adult male mouse subjected to orchiectomy and cholesterol implantation at PD20, and an adult male mouse subjected to orchiectomy and testosterone implantation at PD20. Scale bar indicates $300 \mu \mathrm{m}$. f, fornix; sm, stria medullaris of the thalamus. (B) The volume of the BNSTp in adult male mice. (C) The number of the calbindin-ir cells in the BNSTp of adult male mice. The numbers in the columns indicate the numbers of animals. Differences in values that are significantly $(p<0.05)$ different from each other are indicated with letters.

BNSTp. It was reported that the volume of the BNSTp in adult male rats is reduced by orchiectomy in adulthood (42), whereas orchiectomy in adulthood has no effect on BNSTp volume in guinea pigs (43). Therefore, the results of our current study do not exclude the notion that the formation of the male BNSTp requires testicular testosterone in the postpubertal period as well as the pubertal period. Considering that the BNSTp from PD20 to PD60 expressed the mRNAs of Esr1, Cyp19a1, and Ar, we can deduce that the masculinization of the BNSTp is affected both by testicular testosterone acting via AR and by estradiol, which is synthesized locally in the BNSTp by CYP19A1 from testicular testosterone and acts via ESR1, during the pubertal period. Thus, unlike the defeminization of the AVPV, the masuclinization of the BNSTp is likely established by testicular testosterone and estradiol not only in the perinatal period, but also in the pubertal period. In comparison, the volume and number of calbindin neurons in the BNSTp are lower in adult females than in PD20 females, and ovariectomy on PD20 does not affect the reduction in BNSTp volume or neuron number during puberty (32). Unlike the formation of the male BNSTp, the formation of the female BNSTp may be independent of ovarian hormones during puberty, despite the mRNA expression of Esr1 and Esr2 in this brain structure.

On PD4, the mRNA levels of Esr1 and Cyp19a1 in the BNSTp of $\mathrm{Ar} \mathrm{KO}$ male mice are higher than those in wild-type male mice (23). This suggests that testosterone acting via AR suppresses the mRNA expression of Esr1 and Cyp19a1 in the male BNSTp, thereby reducing estradiol signaling in the early postnatal period. In male mice, the testosterone concentration in blood is gradually increased before puberty and it is higher levels during puberty (PD35 and PD40) (44). Therefore, if the inhibitory action of testosterone on Esr1 and Cyp19a1 mRNA expressions persists until puberty, the action of a large amount of testosterone via AR and lower ESR1 expression in the male BNSTp during puberty might stimulate male-specific development of this structure, as more testosterone would be available to bind the AR (as a lower 
amount would be converted to estradiol, which would also have fewer receptors to signal through). Nonetheless, it was reported that Cyp19a1 mRNA and aromatase activity in the bed nucleus of the stria terminalis (BST) including the BNSTp of adult male rats are enhanced by testosterone actions via $\operatorname{AR}(45,46)$. If this mechanism is functional during puberty as well as adult period, pubertal testosterone may facilitate estrogen production, followed by enhancement of estrogen signaling via ESR. Indeed, a marked less ESR1 in the male BNSTp than in the female BNSTp on PD20-60 may be due to a downregulation of ESR1 by a large amount of aromatized testosterone. Taken together, further experiments are required to determine the relevance between testosterone action via $\mathrm{AR}$ and estradiol action via ESR1 in the BNSTp during puberty in the sexually dimorphic formation of the BNSTp.

\section{Microscopic Isolation of Target Tissues}

In this study, we isolated the AVPV and BNSTp from the brain using the LMD system. The LMD system enables precise and accurate isolation of target regions in sample tissues. This allowed us to detect sex-, age-, and region-dependent differences in the mRNA expression of genes related to sex steroid signaling. In the AVPV, we found that Esr1 mRNA levels were greater in females at PD20-60. However, in one study, the expression of ESR1 protein in the AVPV on PD25 did not differ between the sexes (47). There might be a sex difference in the posttranscriptional stability of Esr $1 \mathrm{mRNA}$ and/or the posttranslational stability of ESR1 protein. In the BNSTp, one study reported that greater Esr1 mRNA expression in female mice is not observed at PD20, but appears by PD60 (48). Another study reported that the murine BNSTp on PD25 contains a greater number of ESR1-immunoreactive cells in females compared with males (47). In this study, although we did not find a significant difference in Esr1 mRNA levels between sexes at each age, we observed higher mRNA levels of Esrl in female mice at PD20-60. Our current study showed no sex difference in Cyp19a1 mRNA expression in the BNSTp. Another study showed that Cyp19a1 mRNA expression in the BST is greater
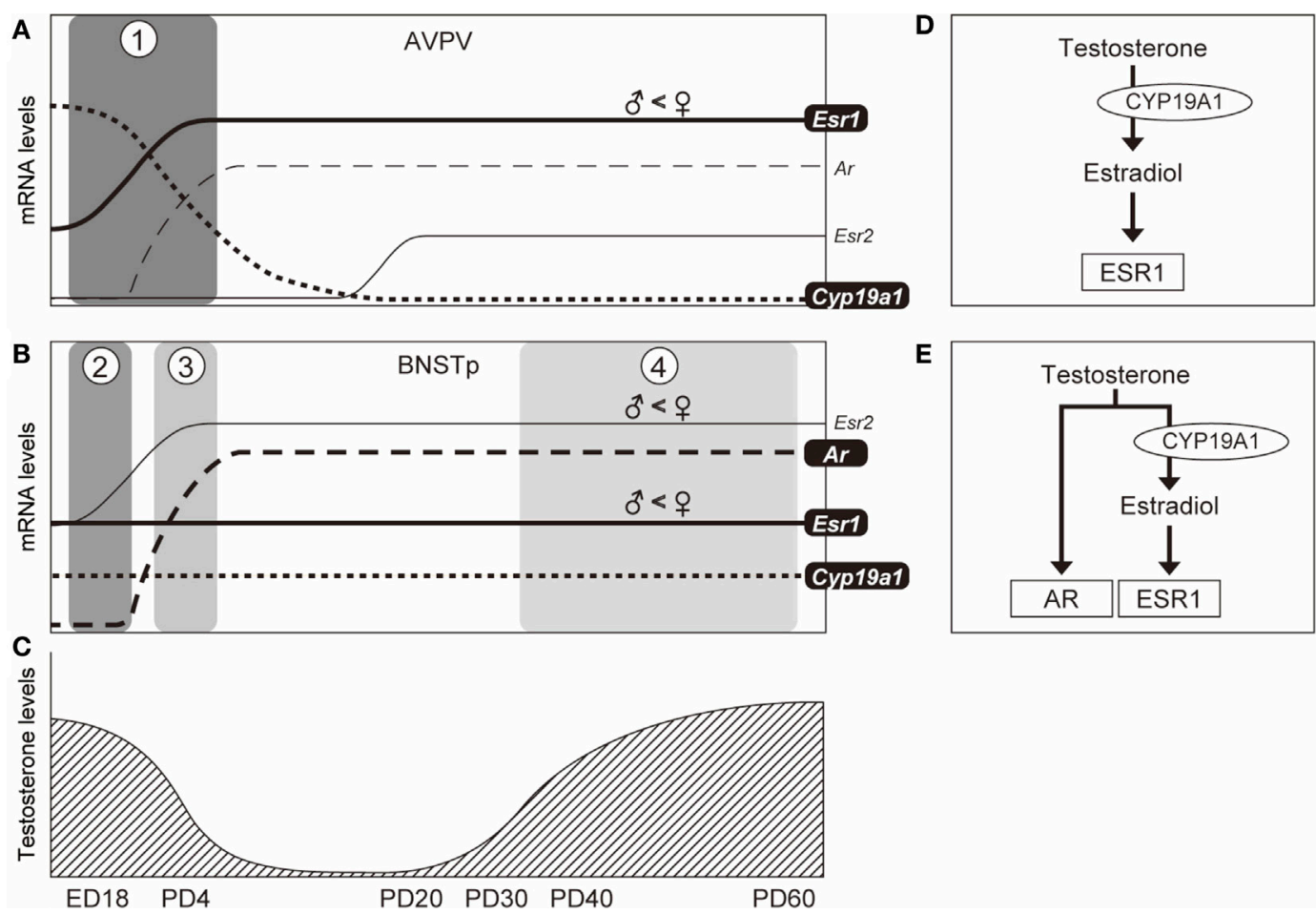

(Schematic ilustration of the temporal expression patterns of genes in the AVPV and BNSTp and possible testicular testosterone actions on the formation of the AVPV and BNSTp in male mice. In the AVPV [panel (A)], based upon our previous (23) and current studies, Esr1 mRNA expression (solid line) increases from embryonic day 18 (ED18) to PD4 and continues in the pubertal period. Cyp19a1 mRNA level (dotted line) decreases from ED18 to PD4 and is not expressed by PD20. Esr1 and Cyp19a1 are essential to the formation of the male AVPV, but Esr2 and Ar are not necessary (23). Testicular testosterone production reaches a peak level at ED18 and decreases after birth (50), and again is increased from PD35 (44) [panel (C)]. The temporal patterns of Esr1, Cyp19a1, and testicular testosterone may indicate that the male AVPV is organized by estradiol (formed by the aromatization of testosterone) signaling through ESR1 during the perinatal period [boxed phase 1 in panel (A) and panel (D)]. In the BNSTp [panel (B)], based upon our previous (23) and current studies, Esr1 mRNA (solid line) is expressed during the perinatal period, and is also expressed during the pubertal period. Cyp19a1 mRNA level (dotted line) is stably expressed in the perinatal and pubertal periods. Ar mRNA (broken line) is not expressed in the late fetal period (ED18), but expressed in the postnatal (PD4) and pubertal periods. Esr1, Cyp19a1, and $A R$ are requisite for the sexual differentiation of the male BNSTp $(23,26)$. The patterns of Esr1, Cyp19a1, Ar, and testicular testosterone levels may indicate that the male BNSTp is formed by the action of estradiol (formed by the aromatization of testicular testosterone) via ESR 1 in the fetal period [boxed phase 2 in panel (B) and pane/ (D)], and both the action of estradiol via ESR1 and testicular testosterone via AR in the postnatal [boxed phase 3 in panel (B) and panel (E)] and pubertal [boxed phase 4 in panel (B) and panel (E)] periods. 
in male mice than in female mice (49). This discordance may be due to a difference of target area. Target area in the previous study was the BST that includes some sub-nuclei (lateral division-dorsal, intermediate, posterior and ventral parts; and medial division-anterior, ventral parts, etc.). By contrast, our current study targeted only the BNSTp (the principal nucleus of the BST posterior division).

In this study, the volume of the AVPV and BNSTp was measured. We found that volume of the AVPV was larger in female mice than that in male mice through PD20 to PD60, although the sex difference was no found at each age. It was previously reported that the sexual dimorphism in AVPV volume in rats emerges between PD30 and PD40 (2). Considering species differences, it is plausible that we correctly isolated AVPV tissues enough to detect sex- and age-related alterations. Regarding the BNSTp, we found a male-biased difference in the volume on PD20-PD60. This sex difference may be resulted from an increase in the volume of the male BNSTp during puberty as reported previously $(28,31,32)$. In this study, there was a tendency that the volume of the male BNSTp increased with age. Taken together, the results that sex differences and age-related alterations in the volume of the AVPV and BNSTp could be acquired in the LMD system may guarantee the accuracy of mRNA expression analysis in the current study.

In conclusion, pubertal testosterone is not converted to estradiol locally in the AVPV because of the absence of Cyp19a1 mRNA. This suggests that estradiol synthesized in the AVPV itself is not able to act on the AVPV. Our previous study showed that Esr1 and Cyp19a1 are necessary genes for the defeminization of the AVPV, but Esr2 and Ar are not, and that Esr1 and Cyp19a1 mRNAs are expressed in the AVPV in the perinatal period (23). Collectively, the male AVPV might be generated by estradiol (formed by the aromatization of testosterone) signaling through ESR1 during the perinatal period, but not during puberty (Figure 6). Additionally, our previous study showed that Esr1, Cyp19a1, and Ar are necessary for the masculinization of

\section{REFERENCES}

1. Bleier R, Byne W, Siggelkow I. Cytoarchitectonic sexual dimorphisms of the medial preoptic and anterior hypothalamic areas in guinea pig, rat, hamster, and mouse. J Comp Neurol (1982) 212(2):118-30. doi:10.1002/cne. 902120203

2. Davis EC, Shryne JE, Gorski RA. Structural sexual dimorphisms in the anteroventral periventricular nucleus of the rat hypothalamus are sensitive to gonadal steroids perinatally, but develop peripubertally. Neuroendocrinology (1996) 63(2):142-8. doi:10.1159/000126950

3. Simerly RB, Swanson LW, Gorski RA. The distribution of monoaminergic cells and fibers in a periventricular preoptic nucleus involved in the control of gonadotropin release: immunohistochemical evidence for a dopaminergic sexual dimorphism. Brain Res (1985) 330(1):55-64. doi:10.1016/00068993(85)90007-1

4. Sumida H, Nishizuka M, Kano Y, Arai Y. Sex differences in the anteroventral periventricular nucleus of the preoptic area and in the related effects of androgen in prenatal rats. Neurosci Lett (1993) 151(1):41-4. doi:10.1016/03043940(93)90040-R

5. Clarkson J, Herbison AE. Postnatal development of kisspeptin neurons in mouse hypothalamus; sexual dimorphism and projections to gonadotropinreleasing hormone neurons. Endocrinology (2006) 147(12):5817-25. doi:10.1210/en.2006-0787 the BNSTp, but Esr2 is not $(23,26)$. Furthermore, we previously reported that the BNSTp expresses Esr1 and Cyp19a1 mRNAs in the perinatal period and $A r$ mRNA in the postnatal period (23). In this study, we found that the BNSTp expresses Esr1, Cyp19a1, and $A r$ in the pubertal period. Additionally, the results of the histological analysis of the BNSTp suggest that testicular testosterone during puberty affects the formation of the BNSTp in male mice. The findings of our current study may indicate that the masculinization of the BNSTp is affected by testosterone, via AR, and by estradiol (formed by the aromatization of testosterone) via ESR1 during puberty. Thus, the sexually dimorphic development of the BNSTp in males might be accomplished by testicular testosterone in the postnatal and pubertal periods as well as by estradiol derived from testosterone in the perinatal and pubertal periods (Figure 6).

\section{ETHICS STATEMENT}

All animal experimental procedures were approved by the Animal Care and Experimentation Committee of Saitama University and were conducted in accordance with the Guidelines for the Care and Use of Experimental Animals of Saitama University.

\section{AUTHOR CONTRIBUTIONS}

MK performed the experiments, analyzed the data, and prepared the manuscript. MM performed the experiments and analyzed the data. ST designed the experiments, analyzed the data, and prepared the manuscript.

\section{FUNDING}

This work was supported by Grants-in-Aid for Scientific Research from the Japan Society for the Promotion of Science (No. $17 \mathrm{~K} 08567$ to ST).

6. Kauffman AS, Gottsch ML, Roa J, Byquist AC, Crown A, Clifton DK, et al. Sexual differentiation of Kiss1 gene expression in the brain of the rat. Endocrinology (2007) 148(4):1774-83. doi:10.1210/en.2006-1540

7. Scott N, Prigge M, Yizhar O, Kimchi T. A sexually dimorphic hypothalamic circuit controls maternal care and oxytocin secretion. Nature (2015) 525(7570):519-22. doi:10.1038/nature15378

8. Smith JT, Popa SM, Clifton DK, Hoffman GE, Steiner RA. Kiss1 neurons in the forebrain as central processors for generating the preovulatory luteinizing hormone surge. J Neurosci (2006) 26(25):6687-94. doi:10.1523/ JNEUROSCI.1618-06.2006

9. Robertson JL, Clifton DK, de la Iglesia HO, Steiner RA, Kauffman AS. Circadian regulation of Kiss1 neurons: implications for timing the preovulatory gonadotropin-releasing hormone/luteinizing hormone surge. Endocrinology (2009) 150(8):3664-71. doi:10.1210/en.2009-0247

10. Forger NG, Rosen GJ, Waters EM, Jacob D, Simerly RB, de Vries GJ. Deletion of Bax eliminates sex differences in the mouse forebrain. Proc Natl Acad Sci U S A (2004) 101(37):13666-71. doi:10.1073/pnas.0404644101

11. del Abril A, Segovia S, Guillamon A. The bed nucleus of the stria terminalis in the rat: regional sex differences controlled by gonadal steroids early after birth. Brain Res (1987) 429(2):295-300. doi:10.1016/0165-3806 (87)90110-6

12. Guillamon A, Segovia S, del Abril A. Early effects of gonadal steroids on the neuron number in the medial posterior region and the lateral division of the 
bed nucleus of the stria terminalis in the rat. Brain Res Dev Brain Res (1988) 44(2):281-90. doi:10.1016/0165-3806(88)90226-X

13. Hines M, Allen LS, Gorski RA. Sex differences in subregions of the medial nucleus of the amygdala and the bed nucleus of the stria terminalis of the rat. Brain Res (1992) 579(2):321-6. doi:10.1016/0006-8993(92)90068-K

14. Caldwell HK, Lee HJ, Macbeth AH, Young WS III. Vasopressin: behavioral roles of an "original" neuropeptide. Prog Neurobiol (2008) 84(1):1-24. doi:10.1016/j.pneurobio.2007.10.007

15. Rood BD, Stott RT, You S, Smith CJ, Woodbury ME, De Vries GJ. Site of origin of and sex differences in the vasopressin innervation of the mouse (Mus musculus) brain. J Comp Neurol (2013) 521(10):2321-58. doi:10.1002/ cne. 23288

16. Rood BD, Murray EK, Laroche J, Yang MK, Blaustein JD, De Vries GJ. Absence of progestin receptors alters distribution of vasopressin fibers but not sexual differentiation of vasopressin system in mice. Neuroscience (2008) 154(3):911-21. doi:10.1016/j.neuroscience.2008.03.087

17. De Vries GJ, al-Shamma HA. Sex differences in hormonal responses of vasopressin pathways in the rat brain. J Neurobiol (1990) 21(5):686-93. doi:10.1002/neu.480210503

18. Bielsky IF, Hu SB, Ren X, Terwilliger EF, Young LJ. The V1a vasopressin receptor is necessary and sufficient for normal social recognition: a gene replacement study. Neuron (2005) 47(4):503-13. doi:10.1016/j.neuron.2005. 06.031

19. Bielsky IF, Hu SB, Young LJ. Sexual dimorphism in the vasopressin system: lack of an altered behavioral phenotype in female $\mathrm{V}$ la receptor knockout mice. Behav Brain Res (2005) 164(1):132-6. doi:10.1016/j.bbr. 2005.06.005

20. Forger NG. Control of cell number in the sexually dimorphic brain and spinal cord. J Neuroendocrinol (2009) 21(4):393-9. doi:10.1111/j.1365-2826. 2009.01825.x

21. Tsukahara S. Sex differences and the roles of sex steroids in apoptosis of sexually dimorphic nuclei of the preoptic area in postnatal rats. J Neuroendocrinol (2009) 21(4):370-6. doi:10.1111/j.1365-2826.2009.01855.x

22. Simerly RB. Hormonal control of the development and regulation of tyrosine hydroxylase expression within a sexually dimorphic population of dopaminergic cells in the hypothalamus. Brain Res Mol Brain Res (1989) 6(4):297-310. doi:10.1016/0169-328X(89)90075-2

23. Kanaya M, Tsuda MC, Sagoshi S, Nagata K, Morimoto C, Thu CK, et al. Regional difference in sex steroid action on formation of morphological sex differences in the anteroventral periventricular nucleus and principal nucleus of the bed nucleus of the stria terminalis. PLoS One (2014) 9(11):e112616. doi:10.1371/journal.pone.0112616

24. Patchev AV, Gotz F, Rohde W. Differential role of estrogen receptor isoforms in sex-specific brain organization. FASEB J (2004) 18(13):1568-70. doi:10.1096/ f. 04-1959fje

25. Hisasue S, Seney ML, Immerman E, Forger NG. Control of cell number in the bed nucleus of the stria terminalis of mice: role of testosterone metabolites and estrogen receptor subtypes. J Sex Med (2010) 7(4 Pt 1):1401-9. doi:10.1111/j.1743-6109.2009.01669.x

26. Tsukahara S, Tsuda MC, Kurihara R, Kato Y, Kuroda Y, Nakata M, et al. Effects of aromatase or estrogen receptor gene deletion on masculinization of the principal nucleus of the bed nucleus of the stria terminalis of mice. Neuroendocrinology (2011) 94(2):137-47. doi:10.1159/000327541

27. Juntti SA, Tollkuhn J, Wu MV, Fraser EJ, Soderborg T, Tan S, et al. The androgen receptor governs the execution, but not programming, of male sexual and territorial behaviors. Neuron (2010) 66(2):260-72. doi:10.1016/j. neuron.2010.03.024

28. Schulz KM, Zehr JL, Salas-Ramirez KY, Sisk CL. Testosterone programs adult social behavior before and during, but not after, adolescence. Endocrinology (2009) 150(8):3690-8. doi:10.1210/en.2008-1708

29. Juraska JM, Sisk CL, DonCarlos LL. Sexual differentiation of the adolescent rodent brain: hormonal influences and developmental mechanisms. Horm Behav (2013) 64(2):203-10. doi:10.1016/j.yhbeh.2013.05.010

30. Gilmore RF, Varnum MM, Forger NG. Effects of blocking developmental cell death on sexually dimorphic calbindin cell groups in the preoptic area and bed nucleus of the stria terminalis. Biol Sex Differ (2012) 3:5. doi:10.1186/2042-6410-3-5

31. Wittmann W, McLennan IS. The bed nucleus of the stria terminalis has developmental and adult forms in mice, with the male bias in the developmental form being dependent on testicular AMH. Horm Behav (2013) 64(4):605-10. doi:10.1016/j.yhbeh.2013.08.017

32. Morishita M, Maejima S, Tsukahara S. Gonadal hormone-dependent sexual differentiation of a female-biased sexually dimorphic cell group in the principal nucleus of the bed nucleus of the stria terminalis in mice. Endocrinology (2017) 158(10):3512-25. doi:10.1210/en.2017-00240

33. Ahmed EI, Zehr JL, Schulz KM, Lorenz BH, DonCarlos LL, Sisk CL. Pubertal hormones modulate the addition of new cells to sexually dimorphic brain regions. Nat Neurosci (2008) 11(9):995-7. doi:10.1038/nn.2178

34. Piekarski DJ, Johnson CM, Boivin JR, Thomas AW, Lin WC, Delevich K, et al. Does puberty mark a transition in sensitive periods for plasticity in the associative neocortex? Brain Res (2017) 1654(Pt B):123-44. doi:10.1016/j. brainres.2016.08.042

35. Shughrue PJ, Bushnell CD, Dorsa DM. Estrogen receptor messenger ribonucleic acid in female rat brain during the estrous cycle: a comparison with ovariectomized females and intact males. Endocrinology (1992) 131(1):381-8. doi:10.1210/endo.131.1.1612018

36. Zhou Y, Shughrue PJ, Dorsa DM. Estrogen receptor protein is differentially regulated in the preoptic area of the brain and in the uterus during the rat estrous cycle. Neuroendocrinology (1995) 61(3):276-83. doi:10.1159/000126849

37. Leite C, Madeira MD, Sa SI. Effects of sex steroids and estrogen receptor agonists on the expression of estrogen receptor alpha in the principal division of the bed nucleus of the stria terminalis of female rats. Brain Res (2014) 1582:99-106. doi:10.1016/j.brainres.2014.07.041

38. Feng Y, Weijdegard B, Wang T, Egecioglu E, Fernandez-Rodriguez J, Huhtaniemi I, et al. Spatiotemporal expression of androgen receptors in the female rat brain during the oestrous cycle and the impact of exogenous androgen administration: a comparison with gonadally intact males. Mol Cell Endocrinol (2010) 321(2):161-74. doi:10.1016/j.mce.2010.02.029

39. Franklin KBJ, Paxinos G. The Mouse Brain in Stereotaxic Coordinates. 3rd ed. San Diego, CA: Academic Press (2008).

40. Faul F, Erdfelder E, Lang AG, Buchner A. G*Power 3: a flexible statistical power analysis program for the social, behavioral, and biomedical sciences. Behav Res Methods (2007) 39(2):175-91. doi:10.3758/BF03193146

41. Mannan MA, O'Shaughnessy PJ. Steroidogenesis during postnatal development in the mouse ovary. J Endocrinol (1991) 130(1):101-6. doi:10.1677/ joe. 0.1300101

42. Malsbury CW, McKay K. Neurotrophic effects of testosterone on the medial nucleus of the amygdala in adult male rats. J Neuroendocrinol (1994) 6(1):57-69. doi:10.1111/j.1365-2826.1994.tb00555.x

43. Hines M, Davis FC, Coquelin A, Goy RW, Gorski RA. Sexually dimorphic regions in the medial preoptic area and the bed nucleus of the stria terminalis of the guinea pig brain: a description and an investigation of their relationship to gonadal steroids in adulthood. J Neurosci (1985) 5(1):40-7. doi:10.1523/JNEUROSCI.05-01-00040.1985

44. Stephens SB, Chahal N, Munaganuru N, Parra RA, Kauffman AS. Estrogen stimulation of Kiss1 expression in the medial amygdala involves estrogen receptor-alpha but not estrogen receptor-beta. Endocrinology (2016) 157(10):4021-31. doi:10.1210/en.2016-1431

45. Roselli CE. Sex differences in androgen receptors and aromatase activity in microdissected regions of the rat brain. Endocrinology (1991) 128(3):1310-6. doi:10.1210/endo-128-3-1310

46. Roselli CE, Resko JA. Sex differences in androgen-regulated expression of cytochrome P450 aromatase in the rat brain. J Steroid Biochem Mol Biol (1997) 61(3-6):365-74. doi:10.1016/S0960-0760(97)80034-9

47. Brock O, De Mees C, Bakker J. Hypothalamic expression of oestrogen receptor alpha and androgen receptor is sex-, age- and region-dependent in mice. J Neuroendocrinol (2015) 27(4):264-76. doi:10.1111/jne.12258

48. Kelly DA, Varnum MM, Krentzel AA, Krug S, Forger NG. Differential control of sex differences in estrogen receptor alpha in the bed nucleus of the stria terminalis and anteroventral periventricular nucleus. Endocrinology (2013) 154(10):3836-46. doi:10.1210/en.2013-1239

49. Stanic D, Dubois S, Chua HK, Tonge B, Rinehart N, Horne MK, et al. Characterization of aromatase expression in the adult male and female mouse brain. I. Coexistence with oestrogen receptors alpha and beta, and androgen receptors. PLoS One (2014) 9(3):e90451. doi:10.1371/journal. pone. 0090451

50. O'Shaughnessy PJ, Baker P, Sohnius U, Haavisto AM, Charlton HM, Huhtaniemi I. Fetal development of Leydig cell activity in the mouse is 
independent of pituitary gonadotroph function. Endocrinology (1998) 139 (3):1141-6. doi:10.1210/endo.139.3.5788

Conflict of Interest Statement: The authors declare that the research was conducted in the absence of any commercial or financial relationships that could be construed as a potential conflict of interest.
Copyright (๑) 2018 Kanaya, Morishita and Tsukahara. This is an open-access article distributed under the terms of the Creative Commons Attribution License (CC BY). The use, distribution or reproduction in other forums is permitted, provided the original author(s) and the copyright owner are credited and that the original publication in this journal is cited, in accordance with accepted academic practice. No use, distribution or reproduction is permitted which does not comply with these terms. 